\title{
A Necessidade Mais Urgente: Adquirir Nossa Própria Experiência*
}

\author{
Protásio L. da Luz
}

São Paulo, SP

Durante a apresentação de alguns grandes estudos multicêntricos no recente Congresso da American Heart Association, em New Orleans, fiquei pensando sobre a situação do Brasil no contexto da cardiologia mundial e as responsabilidades de cada um de nós.

Somos um país de, aproximadamente, 170 milhões de habitantes. No Brasil, temos mais de 150 centros médicos que fazem cirurgia cardíaca, onde se realizaram 44.006 operações cardíacas no ano de 1999. Ainda no mesmo ano foram realizadas, somente pelo SUS, 1.013.414 internações por doenças circulatórias, 54.125 cinecoronariografias, implantados 11.284 marcapassos e feitas 16.186 angioplastias. Temos vários laboratórios bem equipados, de subespecialidades, como eletrofisiologia e imagens, incluindo radioisótopos, ecocardiografia e ressonância magnética. Além disso, temos mais de 80 escolas médicas e 156 hospitais universitários. Ou seja, o volume de pacientes e a variedade de serviços prestados estão entre os maiores do mundo.

No entanto, não temos dados nacionais adequados sobre fatores de risco coronarianos, sobre morbidade e mortalidade de muitas das doenças cardíacas mais comuns, como insuficiência cardíaca ou cardiopatias congênitas. Não temos dados concretos sobre recursos e custos de nossas atividades médicas. Não temos registros

Adequados que permitam o seguimento de pacientes submetidos a investigações e tratamentos, enquanto hospitalizados. Assim, faltam-nos dados evolutivos de crianças operadas de cardiopatias congênitas, de pacientes com infarto, de cirurgias cardíacas de adultos (revascularizações, cirurgias valvares, vasculares) ou pós-angioplas-

Instituto do Coração do Hospital das Clínicas - FMUSP

Correspondência: Protásio L. da Luz - InCor - Unidade de Aterosclerose - Av. Dr.

Enéas C. Aguiar, 44 - 05403-000 - São Paulo, SP

Recebido para publicação em 21/3/01

Aceito em 25/4/01

* Transcrito de Luz, PL Nem só de Ciência se Faz a Cura"

São Paulo: Atheneu, 2001, com autorização do autor e da Editora tias. Por isso, não temos experiências nacionais, verdadeiramente abrangentes e confiáveis, essencialmente, em nenhuma área da cardiologia. Sobre praticamente qualquer tema, quando precisamos discuti-lo quanto à prevalência, incidência ou custos, temos de recorrer a dados estrangeiros.

Também não temos prestado uma contribuição de peso, em nível mundial, testando hipóteses científicas importantes que necessitem comprovação clínica, como seria de se esperar de um país tão vasto, com tal volume de serviços médicos e com tamanho potencial universitário. Como consequiência, o país não é reconhecido como uma potência científica mundial, embora algumas contribuições recentes, como o estudo genômico da Xylela fastidiosa ${ }^{1}$, tenham merecido destaque na ciência internacional. Por outro lado, alguns de nossos profissionais são conhecidos e respeitados, por sua formação básica, suas contribuições em áreas específicas do conhecimento ou ensino. Certas instituições são respeitadas por fazer medicina de ponta, possuir em seus quadros profissionais capacitados facilidades e equipamentos atualizados. Porém, isso se relaciona à aplicação de conhecimentos médicos, ao exercício profissional e não à geração de conhecimento científico. Como um todo, e no que diz respeito à ciência como tal, nossa participação no cenário científico mundial é pequena, embora e, felizmente, seja crescente. Entre 1981 e 1995, nossa produção científica passou de $0,43 \%$ dos artigos mundiais publicados para $0,82 \%{ }^{2}$. Portanto, apesar de estarmos melhorando, é forçoso reconhecer que falta bastante para adquirirmos notória credibilidade no cenário científico internacional; defeito aliás não apenas brasileiro, mas da América Latina.

O que nos tem levado a essa última posição mencionada? Claro que são muitos fatores, mas três parecem mais evidentes. Primeiro, seria uma questão cultural; por formação e natureza não temos o senso apurado de organização, crítica, disciplina, precisão e determinação, que o trabalho científico requer. Somos mais propensos a negócios; nossa economia está entre as dez maiores do mundo; nossa ciência não. Na maioria das áreas do conhecimento o Brasil ocupa entre o $20^{\circ}$ e o $30^{\circ}$ lugares no número de publicações indexadas pelo Citation Index ${ }^{2}$. O fator cultural, no entan- 
to, pode ser verdadeiro em parte, mas não se aplica a muitas universidades e instituições de ensino, onde se encontram pessoas treinadas e com vocação para a investigação. Em segundo lugar, evoca-se a capacidade científica; teríamos poucos profissionais capacitados a produzir cientificamente. Isso também não é mais de todo verdadeiro. Pode ter sido no passado. Hoje, muitos de nossos profissionais são bem treinados e fizeram sua formação complementar em grandes universidades do exterior onde aperfeiçoaram sua capacidade científica. Em 1995, segundo dados da CAPES ${ }^{2}$, tínhamos 1.159 cursos de mestrado e 616 cursos de doutorado. Formamos cerca de 1.000 doutores no setor de saúde em 1999 nas áreas de ciências biológicas. Todos os indicadores disponíveis mostram que a produção científica brasileira tem aumentado. E mais: nossas instituições participaram, recentemente, de inúmeros projetos clínicos multicêntricos internacionais. Exemplos são os estudos HOPE, OPUS, RAVEL, CADILAC, PAML, RALES... para citar só alguns. Portanto, massa crítica de pesquisadores não é uma limitante crucial. Em terceiro lugar, vem a questão financiamento. De fato, o financiamento de pesquisa no Brasil é restrito, difícil de ser obtido. Os recursos do governo federal são muito reduzidos; gasta-se cerca de $0,7 \%$ do PIB com ciência e tecnologia, em comparação aos $3 \%$ gastos em países como EUA ou Japão. Recentemente, o governo federal criou os fundos de pesquisa, que deverão disponibilizar substanciais recursos para pesquisas na área da saúde, o que deverá ajudar. A indústria farmacêutica, que é a grande parceira de pesquisas de instituições respeitáveis, como a American Heart Association, não investe intensamente no Brasil, porque não acredita que seus investimentos tenham retorno. Essa atitude não pode ser atribuída somente à indústria farmacêutica, mas deriva também do comportamento médico. Compete a nós mostrar que temos capacidade para fazer pesquisa, e assim atrair financiamento da grande indústria. Fontes privadas de recursos, sejam individuais ou de empresas, são ainda precárias no Brasil; aqui também falta-nos um sistema profissionalizado dedicado à captação de recursos para ensino e pesquisa junto a fontes privadas. Precisamos de leis que favoreçam objetivamente pessoas e empresas que queiram contribuir para o desenvolvimento científico do país.

Precisamos reverter essa situação toda. Precisamos das nossas próprias experiências para tratar melhor nossos pacientes, para resolver problemas que nos são próprios, como doença de Chagas, doença reumática ou miocardiopatias. Precisamos de experiências próprias porque a farma- cogenética está mostrando que indivíduos respondem, diferentemente, aos mesmos remédios, dependendo de sua constituição genética ${ }^{3,4}$; temos uma população constituída de uma miscigenação peculiar de brancos, negros, índios e asiáticos que pode ser única no mundo. Precisamos de experiências brasileiras para racionalizar custos e gastos, empregando recursos nas áreas mais necessárias; necessitamos conhecer melhor nossa realidade para otimizar procedimentos e evitar desperdícios.

Podemos fazer isso? Podemos, ao mesmo tempo, adquirir experiências genuinamente brasileiras e elucidar problemas clínicos relevantes? Minha resposta é um sim categórico. Atuando assim, estaremos também impulsionando o desenvolvimento científico sensu latu. Em pequena escala, já estamos fazendo isso com o projeto ANIST (Antioxidant in Stents), que é um estudo multicêntrico, duplo cego, randomizado, exclusivamente nacional, que visa analisar o efeito de probucol sobre a reestenose em pacientes tratados com angioplastia e stents; a inclusão de pacientes foi ser encerrada em 2001 e os resultados deverão ser conhecidos neste mesmo ano. A Sociedade Brasileira de Cardiologia está também fazendo levantamentos nacionais sobre doença coronariana e a Sociedade de Cardiologia do Estado de São Paulo, sobre infarto do miocárdio no estado de São Paulo. Porém, precisamos muito mais do que isso. Precisamos de um esforço nacional consciente, de uma associação de lideranças em torno de projetos bem definidos, especialmente, em investigação clínica. Praticamente, todas as áreas da cardiologia necessitam e podem congregar-se em torno de projetos específicos, sem que cada serviço perca sua individualidade. Se podemos participar de projetos estrangeiros, por que não criamos os nossos próprios? É hora de um esforço conjunto, aproveitando as potencialidades de cada grupo, para criar experiências e capacitações que ajudarão a todos.

É difícil conceber outra iniciativa da cardiologia brasileira que produza ao mesmo tempo tantos dividendos em termos de atendimento médico, análise de recursos, produção científica e prestígio internacional. Considere-se ainda que a realização de projetos dessa ordem traria importantes ensinamentos e capacitação tecnocientífica para os grupos envolvidos, traduzindo-se em melhor atendimento médico, com repercussões positivas para indivíduos e o sistema de saúde em geral. Além disso, considero que tal realização é um dever que a classe médica brasileira - que representa sem dúvida uma elite social - tem para com a sociedade brasileira como um todo.

\section{Referências}

1. The genome sequence of the plant pathogen Xylella fastidiosa. The Xylella fastidiosa Consortium of the Organization for Nucleotide Sequencing and Analysis, São Paulo, Brazil. Nature 2000; 406: 152-7.

2. Política Nacional de Ciência, Tecnologia e Desenvolvimento: Alguns Componentes Fundamentais. XXIII Simpósio Anual da Academia de Ciências do Estado de São Paulo. Publicação ACIESP 2000; 103.
3. Weinstein JN. Pharmacogenomics - teaching old drugs new tricks. New Engl J Med 2000; 343: 1408-9.

4. Evans WE, Relling MV. Pharmacogenomics: translating functional genomics into rational therapeutics. Science 1999; 286 : 487-91. 